\title{
Kinetic Study on Aminolysis of 4-Pyridyl X-Substituted Benzoates: Effect of Substituent X on Reactivity and Reaction Mechanism
}

\author{
Jong Pal Lee, ${ }^{*}$ Ae Ri Bae, ${ }^{\dagger}$ and Ik-Hwan Um ${ }^{\dagger, *}$ \\ Department of Chemistry, Dong-A University, Busan 604-714, Korea. *E-mail: jplee@dau.ac.kr \\ 'Department of Chemistry and Nano Science, Ewha Womans University, Seoul 120-750, Korea. E-mail: ihum@ewha.ac.kr \\ Received March 22, 2011, Accepted April 16, 2011
}

\begin{abstract}
A kinetic study is reported for nucleophilic substitution reactions of 4-pyridyl X-substituted benzoates 7a-e with a series of alicyclic secondary amines in $\mathrm{H}_{2} \mathrm{O}$. The Brønsted-type plot for the reactions of 4-pyridyl benzoate $7 \mathbf{c}$ is linear with $\beta_{\text {nuc }}=0.71$. The corresponding reactions of 2-pyridyl benzoate $\mathbf{6}$, which is less reactive than 7c, resulted in also a linear Brønsted-type plot with $\beta_{\text {nuc }}=0.77$. The fact that the more reactive 7c results in a smaller $\beta_{\text {nuc }}$ value appears to be in accord with the reactivity-selectivity principle. The aminolysis of 7c has been suggested to proceed through a stepwise mechanism in which breakdown of the intermediate is the rate-determining step (RDS). The Hammett plot for the reactions of 7a-e with piperidine consists of two intersecting straight lines, i.e., $\rho_{X}=1.47$ for substrates possessing an electron-donating group (EDG) and $\rho_{X}=$ 0.91 for those possessing an electron-withdrawing group (EWG). In contrast, the corresponding YukawaTsuno plot exhibits excellent linear correlation with $\rho_{\mathrm{X}}=0.79$ and $r=0.56$. Thus, it has been concluded that the nonlinear Hammett plot is not due to a change in the RDS but is caused by stabilization of the ground state of the substrates possessing an EDG through resonance interaction between the EDG and the $\mathrm{C}=\mathrm{O}$ bond of the substrates.
\end{abstract}

Key Words : Aminolysis, 4-Pyridyl benzoate, Rate-determining step, Brønsted-type plot, Yukawa-Tsuno plot

\section{Introduction}

Aminolysis of esters has been reported to proceed through a stepwise mechanism or through a concerted pathway depending on reaction conditions (e.g., solvents, nature of substrate and incoming amines). ${ }^{1-12}$ A nonlinear Brønstedtype plot often observed for aminolysis of esters possessing a good leaving group (e.g., 2,4- or 3,4-dinitrophenoxide) has been suggested as evidence for a change in the rate-determining step (RDS). ${ }^{1-9}$ On the other hand, a linear Brønstedtype plot with $\beta_{\text {nuc }}=0.5 \pm 0.1$ has been reported as evidence for a concerted mechanism. ${ }^{10-13}$

Aminolysis of 2,4-dinitrophenyl benzoate in aqueous medium has been reported to proceed through a stepwise mechanism with a change in the RDS on the basis of a curved Brønsted-type plot, i.e., $\beta_{\text {nuc }}$ decreases from 0.74 to 0.34 as the basicity of the incoming amine increases. ${ }^{6 c}$ However, the corresponding reactions performed in $\mathrm{MeCN}$ have been concluded to proceed through a concerted mechanism on the basis of a linear Brønsted-type plot with $\beta_{\text {nuc }}=0.40 .^{10}$

Changing electrophilic center from $\mathrm{C}=\mathrm{O}$ to $\mathrm{P}=\mathrm{O}$ (or $\mathrm{P}=\mathrm{S}$ ) has been shown to be an important factor to determine reaction mechanisms. Aminolysis of 2,4-dinitrophenyl diphenylphosphinate $\mathbf{1}$ and diphenylphosphinothioate $\mathbf{2}$ in $\mathrm{H}_{2} \mathrm{O}$ have been concluded to proceed through a concerted mechanism on the basis of linear Brønsted-type plots with $\beta_{\text {nuc }}=0.38$ and 0.52 for the reactions of 1 and 2 , respectively. ${ }^{13}$<smiles>O=[N+]([O-])c1ccc(OP(=O)(c2ccccc2)c2ccccc2)c([N+](=O)[O-])c1</smiles><smiles>O=[N+]([O-])c1ccc(OP(=S)(c2ccccc2)c2ccccc2)c([N+](=O)[O-])c1</smiles>

The effect of electrophilic center on reaction mechanism has also been demonstrated to be significant. Aminolysis of 4-nitrophenyl benzoate 3 in $\mathrm{H}_{2} \mathrm{O}$ has been reported to proceed through a stepwise mechanism in which breakdown of the zwitterionic intermediate $\mathrm{T}^{ \pm}$is the RDS on the basis of a linear Brønsted-type plot with $\beta_{\text {nuc }}=0.81{ }^{6 \mathrm{~d}}$ In contrast, the corresponding reactions of $S$-4-nitrophenyl thiobenzoate 4 have been concluded to proceed through a stepwise mechanism with a change in the RDS as the basicity of the incoming amines increases. ${ }^{9}$ Furthermore, aminolysis of $O$ 4-nitrophenyl thionobenzoate $\mathbf{5}$ has been found to proceed though two intermediates (i.e., $\mathrm{T}^{ \pm}$and its deprotonated form $\mathrm{T}^{-}$) on the basis of upward curvature in the plots of observed rate constants $\left(k_{\mathrm{obsd}}\right)$ versus amine concentrations. ${ }^{7}$

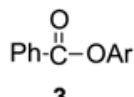

3

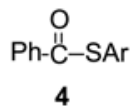

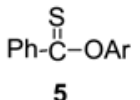

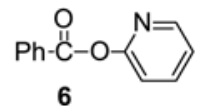

We have recently reported that aminolysis of 2-pyridyl benzoate 6 in $\mathrm{H}_{2} \mathrm{O}$ proceeds through a stepwise mechanism on the basis of a linear Brønsted-type plot with $\beta_{\text {nuc }}=0.77 .^{6 \mathrm{e}}$ Our study has been extended to the reactions of 4-pyridyl Xsubstituted benzoates 7a-e with a series of alicyclic secondary amines to investigate the effect of substituent $\mathrm{X}$ on reactivity and reaction mechanism (Scheme 1). We have 


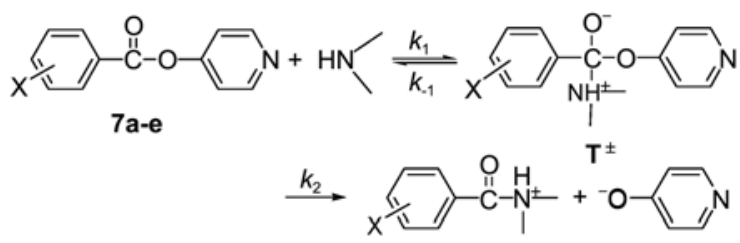

$\mathrm{X}=4-\mathrm{MeO}(7 \mathrm{a}), 4-\mathrm{Me}(7 \mathrm{~b}), \mathrm{H}(7 \mathrm{c}), 4-\mathrm{Cl}(7 \mathrm{~d}), 3-\mathrm{NO}_{2}(7 \mathrm{e})$.

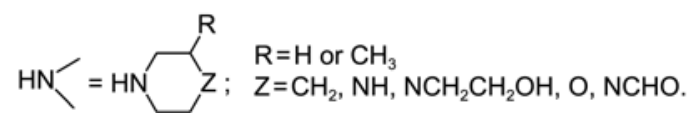

Scheme 1

also studied the effect of changing the leaving group from 2pyridinolate to 4-pyridinolate by comparing the current results with those reported previously for the corresponding reaction of 2-pyridyl benzoate 6 .

\section{Results and Discussion}

The kinetic study was performed spectrophotometrically under pseudo-first-order conditions, e.g., the concentration of amines was kept in excess over the concentration of substrates. All reactions obeyed first-order kinetics and the pseudo-first-order rate constants $\left(k_{\text {obsd }}\right)$ were calculated from the equation, $\ln \left(A_{\infty}-A_{\mathrm{t}}\right)=-k_{\mathrm{obsd}} t+C$. The plots of $k_{\text {obsd }} v s$. [amine] were linear and passed through the origin, indicating that general base catalysis by a second amine molecule is absent and contribution of $\mathrm{H}_{2} \mathrm{O}$ and/or $\mathrm{OH}^{-}$ion from solvolysis of amines to $k_{\text {obsd }}$ is negligible. Thus, the second-order rate constants $\left(k_{\mathrm{N}}\right)$ were calculated from the slope of the linear plots. The uncertainty in the $k_{\mathrm{N}}$ values is estimated to be less than $\pm 3 \%$ from replicate runs. The $k_{\mathrm{N}}$ values determined in this way are summarized in Table 1 for the reactions of 7c with 6 different amines and in Table 2 for the reactions of $7 \mathbf{a}-\mathbf{e}$ with piperidine.

Effect of Amine Baicity on Reactivity. As shown in Table 1, the second-order rate constant for the reactions of 7c decreases as the amine basicity decreases, e.g., $k_{\mathrm{N}}$ decreases from $9.55 \mathrm{M}^{-1} \mathrm{~s}^{-1}$ to 0.822 and $5.73 \times 10^{-2} \mathrm{M}^{-1} \mathrm{~s}^{-1}$ as the $\mathrm{p} K_{\mathrm{a}}$ of the conjugate acid of amines decreases from 11.22 to 9.85 and 7.98, in turn. A similar result is shown for the corresponding reactions of $\mathbf{6}$. However, 6 is up to 6 fold less

Table 1. Summary of second-order rate constants $\left(k_{\mathrm{N}}\right)$ for nucleophilic substitution reactions of 2-pyridyl benzoate 6 and 4-pyridyl benzoate 7c with alicyclic secondary amines in $\mathrm{H}_{2} \mathrm{O}$ at $25.0 \pm 0.1$ ${ }^{\circ} \mathrm{C}^{a}$

\begin{tabular}{llccc}
\hline \multirow{2}{*}{ Entry } & \multirow{2}{*}{ Amines } & $\mathrm{p} K_{\mathrm{a}}$ & \multicolumn{2}{c}{$10^{2} k_{\mathrm{N}} / \mathrm{M}^{-1} \mathrm{~s}^{-1}$} \\
\cline { 3 - 5 } & & $\mathbf{6}$ & $\mathbf{7 c}$ \\
\hline 1 & piperidine & 11.22 & 368 & 955 \\
2 & 3-methylpiperidine & 11.07 & 280 & 797 \\
3 & piperazine & 9.85 & 27.9 & 82.2 \\
4 & 1-(2-hydroxyethyl)piperazine & 9.38 & 8.51 & 22.4 \\
5 & morpholine & 8.65 & 3.42 & 8.90 \\
6 & $N$-formylpiperazine & 7.98 & 0.906 & 5.73 \\
\hline
\end{tabular}

${ }^{a}$ The $\mathrm{p} K_{\mathrm{a}}$ and $k_{\mathrm{N}}$ data for the reactions of $\mathbf{6}$ were taken from ref. $6 \mathrm{e}$.

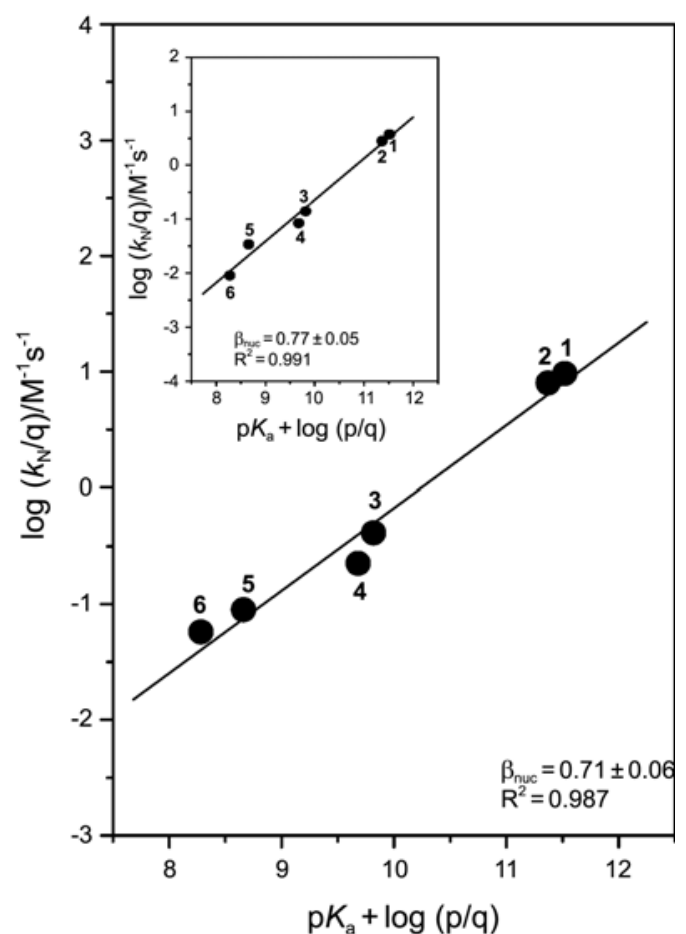

Figure 1. Bronsted-type plots for nucleophilic substitution reactions of 4-pyridyl benzoate 7c and 2-pyridyl benzoate $\mathbf{6}$ (inset) with alicyclic secondary amines in $\mathrm{H}_{2} \mathrm{O}$ at $25.0 \pm 0.1^{\circ} \mathrm{C}$. The identity of points is given in Table 1 .

reactive than 7c. This is in accord with the fact that 4pyridinolate is ca. $0.4 \mathrm{p} K_{\mathrm{a}}$ units less basic than 2-pyridiloate (i.e., $\mathrm{p} K_{\mathrm{a}}=11.06$ and 11.50 for 4-hydroxypyridine and 2hydroxypyridine in $\mathrm{H}_{2} \mathrm{O}$, respectively). ${ }^{14}$

The effect of amine basicity on reactivity is illustrated in Figure 1. The Brønsted-type plot for the reactions of $7 \mathbf{c}$ is linear with $\beta_{\text {nuc }}=0.71$, when $k_{\mathrm{N}}$ and $\mathrm{p} K_{\mathrm{a}}$ values are statistically corrected using $p$ and $q$ (i.e., $p=2$ and $q=1$ except $q=$ 2 for piperazine). ${ }^{15}$ The $\beta_{\text {nuc }}$ value of 0.71 is a lower limit for reactions reported previously to proceed through a stepwise mechanism with breakdown of an intermediate being the RDS. In fact, the corresponding reactions of $\mathbf{6}$ has been concluded to proceed through a stepwise mechanism, in which expulsion of the leaving group occurs in the RDS on the basis of the linear Brønsted-type plot with $\beta_{\text {nuc }}=0.77$ (inset of Fig. 1). ${ }^{6 \mathrm{e}}$ Thus, one can suggest that the reactions of 7c proceed also through a stepwise mechanism and the smaller $\beta_{\text {nuc }}$ value obtained for the reactions of the more reactive $7 \mathbf{c}$ is in accord with the reactivity-selectivity principle (RSP). ${ }^{16}$

Effect of Substituent $X$ on Reactivity and Mechanism. To study the effect of substituent $X$ on reactivity, reactions of 4-pyridyl X-substituted benzoates 7a-e with piperidine have been performed. As shown in Table 2 , the $k_{\mathrm{N}}$ value for the reactions of 7a-e increases as the substituent $X$ in the benzoyl moiety changes from an EDG to an EWG, e.g., it increases from $3.80 \mathrm{M}^{-1} \mathrm{~s}^{-1}$ to 9.55 and $39.8 \mathrm{M}^{-1} \mathrm{~s}^{-1}$ as $\mathrm{X}$ changes from 4-MeO to $\mathrm{H}$ and $3-\mathrm{NO}_{2}$, respectively. The fact that the substrate possessing an EWG in the benzoyl moiety 
Table 2. Summary of second-order rate constants for nucleophilic substitution reactions of 4-pyridyl X-substituted benzoates 7a-e with piperidine in $\mathrm{H}_{2} \mathrm{O}$ at $25.0 \pm 0.1{ }^{\circ} \mathrm{C}$

\begin{tabular}{cccc}
\hline Entry & $\mathrm{X}$ & $\sigma$ & $k_{\mathrm{N}} / \mathrm{M}^{-1} \mathrm{~s}^{-1}$ \\
\hline $\mathbf{7 a}$ & $4-\mathrm{MeO}$ & -0.27 & 3.80 \\
$\mathbf{7 b}$ & $4-\mathrm{Me}$ & -0.17 & 5.54 \\
$\mathbf{7 c}$ & $\mathrm{H}$ & 0 & 9.55 \\
$\mathbf{7 d}$ & $4-\mathrm{Cl}$ & 0.23 & 12.0 \\
$\mathbf{7 e}$ & $3-\mathrm{NO}_{2}$ & 0.71 & 39.8 \\
\hline
\end{tabular}

is more reactive than that bearing an EDG appears to be consistent with the report by Neuvonen et al. that aryl acetates or alkyl benzoates possessing an EWG are more reactive than those bearing an $\mathrm{EDG}^{17}$

Neuvonen et al. have measured ${ }^{13} \mathrm{C}$ NMR shifts of the carbonyl carbon and IR frequencies of the $\mathrm{C}=\mathrm{O}$ stretching vibration in various Y-substituted phenyl X-substituted benzoates and acetates, and found that an EWG in the leaving- or nonleaving-group causes upfield ${ }^{13} \mathrm{C}$ NMR shifts of the carbonyl carbon and higher frequencies of the $\mathrm{C}=\mathrm{O}$ stretching vibration. ${ }^{17}$ Accordingly, it has been concluded that an EWG in the leaving- or nonleaving-group does not increase the electrophilicity of the carbonyl carbon, and the enhanced reactivity of esters possessing an EWG is due to destabilization of the GS of substrates, since an EWG in the leaving group or in the nonleaving benzoyl moiety would inhibit the resonance interactions I $\leftrightarrow$ II $\leftrightarrow$ III. ${ }^{17}$

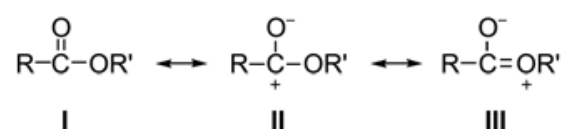

To examine the conclusion drawn by Neuvonen et al., a Hammett plot has been constructed for the reactions of 7a-e with piperidine. As shown in Figure 2, the Hammett plot for the reactions of 7a-e consists of two intersecting straight lines. Interestingly, substrates $\mathbf{7 d}$ and $7 \mathbf{e}$ exhibit negative deviation from the linear line composed of substrates 7a-c. Clearly, this is opposite to the expectation. Because substrates $\mathbf{7 d}$ and $7 \mathbf{e}$ should have exhibited positive deviation from the Hammett plot, if destabilization of the GS through inhibition of resonance interactions were responsible for the high reactivity shown by substrates possessing an EWG. Thus, one can suggest that the high reactivity shown by substrates $\mathbf{7 d}$ and $\mathbf{7 e}$ is not due to GS destabilization through inhibition of resonance interactions.

A nonlinear Hammett plot has traditionally been interpreted as a change in reaction mechanism or RDS depending on the shape of curvature. ${ }^{18,19}$ Upward curvature often found for nucleophilic substitution reactions of benzylic systems has been attributed to a change in mechanism, i.e., from $\mathrm{S}_{\mathrm{N}} 1$ for substrates possessing an EDG to $\mathrm{S}_{\mathrm{N}} 2$ for those bearing an EWG. ${ }^{18,19}$ In contrast, downward curvature has been ascribed to a change in RDS upon changing substituents from EDGs to EWGs. ${ }^{18,19}$ In fact, a downward Hammett plot has been reported for reactions of a series of X-substituted benzaldehydes with ammonia, e.g., benzaldehydes possess-

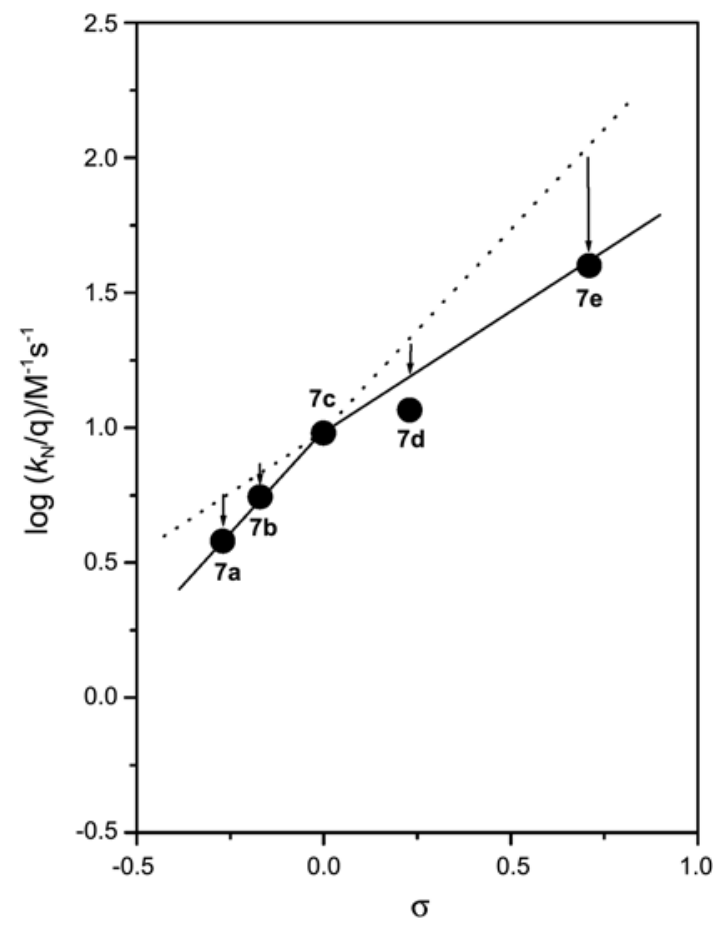

Figure 2. Hammett plot for nucleophilic substitution reactions of 4-pyridyl X-substituted benzoates 7a-e with piperidine in $\mathrm{H}_{2} \mathrm{O}$ at $25.0 \pm 0.1{ }^{\circ} \mathrm{C}$. The identity of points is given in Table 2 .

ing an EDG result in a large positive $\rho$ value while those with an EWG yield a negative $\rho$ value. ${ }^{18 a}$

Therefore, one might attribute the nonlinear Hammett plots shown in Figure 2 to a change in RDS, i.e., from formation of $\mathrm{T}^{ \pm}$to its breakdown to yield the products as the substituent $\mathrm{X}$ in the benzoyl moiety changes from EDGs to EWGs. This idea appears to be reasonable, since one can expect that an EDG in the benzoyl moiety would retard nucleophilic attack (i.e., a decrease in $k_{1}$ ) but would accelerate departure of the negatively charged leaving group (i.e., an increase in $k_{2}$ ). In contrast, an EWG would increase $k_{1}$ but would decrease $k_{2}$. Thus, the nonlinear Hammett plots might be taken as evidence for a change in RDS upon changing the substituent $\mathrm{X}$ in the benzoyl moiety.

Origin of Nonlinear Hammett Plot. However, we propose that the nonlinear Hammett plot in Figure 2 is not due to a change in the RDS. This is because the RDS should be determined by the $k_{2} / k_{-1}$ ratio (i.e., $\mathrm{RDS}=k_{1}$ when $k_{2} / k_{-1}>1$ or RDS $=k_{2}$ when $k_{2} / k_{-1}<1$ ) but not by the magnitude of $k_{1}$ and $k_{2}$. Furthermore, $k_{1}$ and $k_{2}$ values cannot be compared directly, since the former is a second-order rate constant while the latter is a first-order rate constant.

To examine the above argument that the nonlinear Hammett plot shown in Figure 2 is not due to a change in RDS, Yukawa-Tsuno plot has been constructed. The YukawaTsuno equation, eq. (1), has originally been derived to account for solvolysis of benzylic system in which a positive charge develops in the TS. ${ }^{20,21}$ We have recently shown that Yukawa-Tsuno equation is highly effective to elucidate ambiguities in the mechanism for nucleophilic substitution reactions of aryl benzoates, ${ }^{6}$ diphenylphosphinates ${ }^{13}$ and 


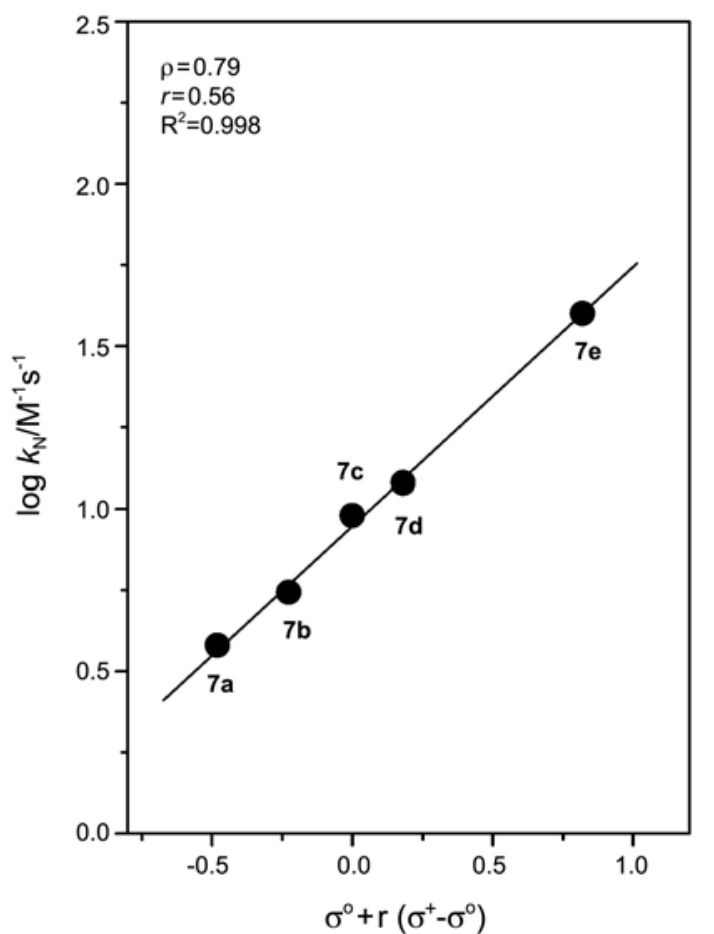

Figure 3. Yukawa-Tsuno plot for nucleophilic substitution reactions of 4-pyridyl X-substituted benzoates 7a-e with piperidine in $\mathrm{H}_{2} \mathrm{O}$ at $25.0 \pm 0.1{ }^{\circ} \mathrm{C}$. The identity of points is given in Table 2 .

related esters. ${ }^{7,8}$

$$
\log \left(k_{\mathrm{X}} / k_{\mathrm{H}}\right)=\rho\left[\sigma_{\mathrm{X}}{ }^{0}+r\left(\sigma_{\mathrm{X}}{ }^{+}-\sigma_{\mathrm{X}}{ }^{\mathrm{o}}\right)\right]
$$

As shown in Figure 3, the Yukawa-Tsuno plot exhibits excellent linear correlation with $\rho=0.79$ and $r=0.56$. Such linear Yukawa-Tsuno plot indicates that the reactions proceed without changing the RDS upon changing the substituent X. Thus, one can conclude that the nonlinear Hammett plot shown in Figure 2 is clearly not due to a change in the RDS.

The $r$ value in eq. (1) represents the resonance demand of the reaction center or the extent of resonance contribution, while the term $\left(\sigma_{X}^{+}-\sigma_{X}{ }^{0}\right)$ is the resonance substituent constant that measures the capacity for $\pi$-delocalization of the $\pi$-electron donor substituent. ${ }^{20,21}$ The $r$ value of 0.56 obtained in this study suggests that the resonance contribution to $k_{\mathrm{N}}$ is somewhat significant.

Resonance structures as modeled by IV and V are possible for substrates possessing an EDG in the benzoyl moiety (e.g., $7 \mathbf{a}$ and $\mathbf{7 b}$ ). Since such resonance structures stabilize the GS of the substrates, one can suggest that stabilization of the GS through resonance interactions is responsible for the negative deviation exhibited by substrates possessing an EDG from the Hammett plot shown in Figure 2. This argument can be further supported by the fact that the substrate possessing a stronger EDG (e.g., 7a) deviates more significantly from the linear Hammett plot composed of 7c-e. Thus, one can conclude that substrates possessing an EDG are less reactive than would be expected from their $\sigma$ constant due to stabilization of their GS through resonance interaction.

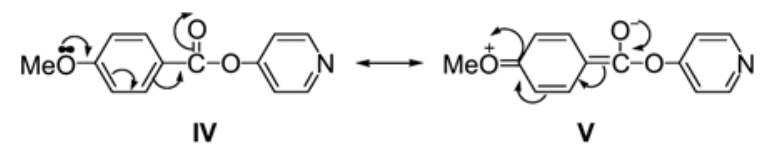

A similar conclusion has been drawn for solvolysis of methyl chloroformate and acetyl chloride in aqueous acetone. The former was reported to be $9 \times 10^{3}$ times less reactive than the latter. ${ }^{22}$ Kevill et al. have concluded that stabilization of the GS through the resonance interaction VI $\leftrightarrow$ VII, analogous to that proposed in the current system (i.e., IV $\leftrightarrow \mathrm{V}$ ), is responsible for the decreased reactivity of methyl chloroformate, since such resonance interactions are not possible for acetyl chloride. ${ }^{22}$

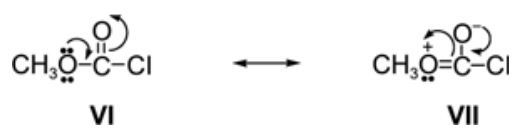

\section{Conclusions}

The current study has allowed us to conclude the following: (1) 4-Pyridyl benzoate $7 \mathbf{c}$ is more reactive than 2pyridyl benzoate 6 , which is in accord with the fact that 7c possesses a less basic leaving group than 6. (2) The Brønsted-type plot for the reactions of $7 \mathbf{c}$ is linear with $\beta_{\text {nuc }}=$ 0.71 . The reactions of $\mathbf{7} \mathbf{c}$ have been suggested to proceed through a stepwise mechanism with breakdown of an intermediate being the RDS on the basis of the linear Brønstedtype plot with $\beta_{\text {nuc }}=0.71$. (3) The Hammett plot for the reactions of 7a-e consists of two intersecting straight lines. However, the nonlinear Hammett plot is not due to a change in RDS. (4) The Yukawa-Tsuno plot for the reactions of 7a-e exhibits excellent linear correlation with $\rho=0.79$ and $r=$ 0.56 , indicating that resonance stabilization of substrates possessing an EDG (e.g., $7 \mathbf{a}$ and $\mathbf{7 b}$ ) is responsible for the nonlinear Hammett plot. (5) The high reactivity shown by substrates possessing an EWG (e.g., 7d and 7e) is not due to GS destabilization.

\section{Experimental Section}

Materials. Substrates 7a-e were readily prepared from the reaction of X-substituted benzoyl chloride with 4-hydroxypyridine in anhydrous ether as reported previously. ${ }^{6 e}$ Their purity was confirmed from melting point and spectral data such as ${ }^{1} \mathrm{H}$ NMR. Secondary amines and other chemicals were of the highest quality available. Doubly glass distilled water was further boiled and cooled under nitrogen just before use.

Kinetics. The kinetic study was performed using a UV-vis spectrophotometer equipped with a constant temperature circulating bath to keep the reaction temperature at $25.0 \pm$ $0.1{ }^{\circ} \mathrm{C}$. All the reactions were carried out under pseudo-firstorder conditions in which the amine concentration was at least 20 times greater than the substrate concentration. Typically, the reaction was initiated by adding $5 \mu \mathrm{L}$ of a 0.02 $\mathrm{M}$ of substrate stock solution in $\mathrm{MeCN}$ by a $10 \mu \mathrm{L}$ syringe to 
a $10 \mathrm{~mm}$ UV cell containing $2.50 \mathrm{~mL}$ of the reaction medium and amine nucleophile. The reactions were followed by monitoring the leaving 4-pyridinolate.

Product Analysis. 4-Pyridinolate was liberated and identified as one of the reaction products by comparison of the UV-vis spectra after completing the reactions with those of authentic samples under the same kinetic conditions.

Acknowledgments. This study was supported by the Dong-A University research fund.

\section{References}

1. (a) Jencks, W. P. Chem. Rev. 1985, 85, 511-527. (b) Castro, E. A. Chem. Rev. 1999, 99, 3505-3524. (c) Castro, E. A. Pure Appl. Chem. 2009, 81, 685-696. (d) Page, M. I.; Williams, A. Organic and Bio-organic Mechanisms; Longman: Singapore, 1997; Chapter 7.

2. (a) Menger, F. M.; Smith, J. H. J. Am. Chem. Soc. 1972, 94, 38243829. (b) Gresser, M. J.; Jencks, W. P. J. Am. Chem. Soc. 1977, 99, 6970-6980. (c) Maude, A. B.; Williams, A. J. Chem. Soc., Perkin Trans. 2 1997, 179-183. (d) Cook, R. D.; Daouk, W. A.; Hajj, A. N.; Kabbani, A.; Kurku, A.; Samaha, M.; Shayban, F.; Tanielian, O. V. Can. J. Chem. 1986, 64, 213-219.

3. (a) Castro, E. A.; Aliaga, M.; Santos, J. G. J. Org. Chem. 2005, 70, 2679-2685. (b) Castro, E. A.; Gazitua, M.; Santos, J. G. J. Org. Chem. 2005, 70, 8088-8092. (c) Castro, E. A.; Aliaga, M.; Santos, J. G. J. Org. Chem. 2004, 69, 6711-6714. (d) Castro, E. A.; Cubillos, M.; Santos, J. G. J. Org. Chem. 2004, 69, 4802-4807. (e) Castro, E. A.; Cubillos, M.; Aliaga, M.; Evangelisti, S.; Santos, J. G. J. Org. Chem. 2004, 69, 2411-2416. (f) Castro, E. A.; Acuña, M.; Soto, C.; Trujillo, C.; Vásquez, B.; Santos, G. J. Phys. Org. Chem. 2008, 21, 816-822. (g) Galabov, B.; Ilieva, S.; Hadjieva, B.; Atanasov, Y.; Schaefer, H. F., III J. Phys. Chem. A 2008, 112, 6700-6707. (h) Castro, E. A.; Gazitua, M.; Rios, P.; Tobar, P.; Santos, J. G. J. Phys. Org. Chem. 2009, 22, 443-448. (i) Castro, E. A.; Gazitua, M.; Santos, J. G. J. Phys. Org. Chem. 2009, 22, 10031008. (j) Castro, E. A.; Gazitua, M.; Santos, J. G. J. Phys. Org. Chem. 2009, 22, 1030-1037.

4. (a) Oh, H. K.; Oh, J. Y.; Sung, D. D.; Lee, I. J. Org. Chem. 2005, 70, 5624-5629. (b) Lee, I.; Sung, D. D. Curr. Org. Chem. 2004, 8, 557-567. (c) Oh, H. K.; Park, J. E.; Sung, D. D.; Lee, I. J. Org. Chem. 2004, 69, 9285-9288. (d) Oh, H. K.; Ha, J. S.; Sung, D. D.; Lee, I. J. Org. Chem. 2004, 69, 8219-8223. (e) Oh, H. K.; Park, J. E.; Sung, D. D.; Lee, I. J. Org. Chem. 2004, 69, 3150-3153.

5. (a) Hoque, M. E.; Guha, A. K.; Kim, C. K.; Lee, B.; Lee, H. W. Org. Biomol. Chem. 2009, 7, 2919-2925. (b) Dey, N. K.; Hoque. M. E.; Kim, C. K.; Lee, B.; Lee, H. W. J. Phys. Org. Chem. 2009, 22, 425-430. (c) Lee, J. P.; Lee. H. W.; Okuyama, T.; Koo, I. S. Bull. Korean Chem. Soc. 2009, 30, 1893-1894. (d) Dey, N. K.; Kim, C. K.; Lee, H. W. Bull. Korean Chem. Soc. 2009, 30, 975978. (e) Lumbiny, B. J.; Lee, H. W. Bull. Korean Chem. Soc. 2008, 29, 2065-2068.

6. (a) Um, I. H.; Im, L. R.; Kim, E. H.; Shin, J. H. Org. Biomol. Chem. 2010, 8, 3801-3806. (b) Um, I. H.; Lee, J. Y.; Ko, S. H.; Bae, S. K. J. Org. Chem. 2006, 71, 5800-5803. (c) Um, I. H.; Kim, K. H.; Park, H. R.; Fujio, M.; Tsuno, Y. J. Org. Chem. 2004, 69, 3937-3942. (d) Um, I. H.; Min, J. S.; Ahn, J. A.; Hahn, H. J. J. Org. Chem. 2000, 65, 5659-5663. (e) Lee, J. P.; Im, L. R.; Bae, A. R.; Um, I. H. Bull. Korean Chem. Soc. 2010, 31, 3588- 3592.

7. (a) Um, I. H.; Yoon, S.; Park, H. R.; Han, H. J. Org. Biomol. Chem. 2008, 6, 1618-1624. (b) Um, I. H.; Hwang, S. J.; Yoon, S.; Jeon, S. E.; Bae, S. K. J. Org. Chem. 2008, 73, 7671-7677. (c) Um, I. H.; Hwang, S. J.; Baek, M. H.; Park, E. J. J. Org. Chem.
2006, 71, 9191-9197. (d) Um, I. H.; Kim, E. Y.; Park, H. R.; Jeon, S. E. J. Org. Chem. 2006, 71, 2302-2306. (e) Um, I. H.; Han, H. J.; Back, M. H.; Bae. S. Y. J. Org. Chem. 2004, 69, 6365-6370. (f) Um, I. H.; Lee, S. E.; Kwon, H. J. J. Org. Chem. 2002, 67, 89999005.

8. (a) Um, I. H.; Hong, J. Y.; Seok, J. A. J. Org. Chem. 2005, 70, 1438-1444. (b) Um, I. H.; Chun, S. M.; Chae, O. M.; Fujio, Mizue.; Tsuno, Y. J. Org. Chem. 2004, 69, 3166-3172. (c) Um, I. H.; Hong, J. Y.; Kim, J. J.; Chae, O. M.; Bae, S. K. J. Org. Chem. 2003, 68, 5180-5185.

9. (a) Um, I. H.; Park, Y. M.; Ahn, J. A. Bull. Korean Chem. Soc. 2009, 30, 214-218. (b) Castro, E. A.; Aguayo, R.; Bessolo, J.; Santos, J. G. J. Org. Chem. 2005, 70, 7788-7791.

10. Um, I. H.; Jeon, S. E.; Seok, J. A. Chem. Eur. J. 2006, 12, 12371243.

11. (a) Castro, E. A.; Gazitua, M.; Santos, J. G. J. Phys. Org. Chem. 2008, 21, 271-278. (b) Castro, E. A.; Cepeda, M.; Pavez, P.; Santos, J. G. J. Phys. Org. Chem. 2009, 22, 455-459. (c) Castro, E. A.; Ramos, M.; Santos, J. G. J. Org. Chem. 2009, 74, 6374-6377.

12. Williams, A. Acc. Chem. Res. 1989, 22, 387-392.

13. (a) Um, I. H.; Han, J. Y.; Shin, Y. H. J. Org. Chem. 2009, 74, 3073-3078. (b) Um, I. H.; Akhtar, K.; Shin, Y. H.; Han, J. Y. J. Org. Chem. 2007, 72, 3823-3829. (c) Um, I. H.; Shin, Y. H.; Han, J. Y.; Mishima, M. J. Org. Chem. 2006, 71, 7715-7720.

14. Jencks, W. P.; Regenstein, F. In Handbook of Biochemistry, Selected Data for Molecular Biology; Sober, H. A., Ed.; The Chemical Rubber Co.: Cleveland, OH, 1968.

15. Bell, R. P. The Proton in Chemistry; Methuen: London, 1959; p 159.

16. Lowry, T. H.; Richardson, K. S. Mechanism and Theory in Organic Chemistry, $3^{\text {rd }}$ ed.; Harper/Collins: New York, 1987; p 148.

17. (a) Neuvonen, H.; Neuvonen, K.; Koch, A.; Kleinpeter, E. J. Chem. Phys. A 2005, 109, 6279-6289. (b) Neuvonen, H.; Neuvonen, K.; Pasanen, P. J. Org. Chem. 2004, 69, 3794-3800. (c) Neuvonen, H.; Neuvonen, K.; Koch, A.; Kleinpeter, E.; Pasanen, P. J. Org. Chem. 2002, 67, 6995-7003. (d) Neuvonen, H.; Neuvonen, K. J. Chem. Soc. Perkin Trans 1999, 2, 1497-1502.

18. (a) Carroll, F. A. Perspectives on Structure and Mechanism in Organic Chemistry; Brooks/Cole: New York, 1998; pp 371-386. (b) Jencks, W. P. Catalysis in Chemistry and Enzymology; McGraw-Hill: New York, 1969; pp 480-483.

19. (a) Swansburg, S.; Buncel, E.; Lemieux, R. P. J. Am. Chem. Soc. 2000, 122, 6594-6600. (b) Pross, A. Theoretical \& Physical Principles of Organic Reactivity; Wiley \& Sons: New York, 1995; pp 165-169.

20. (a) Tsuno, Y.; Fujio, M. Adv. Phys. Org. Chem. 1999, 32, 267-385. (b) Tsuno, Y.; Fujio, M. Chem. Soc. Rev. 1996, 25, 129-139. (c) Yukawa, Y.; Tsuno, Y. Bull. Chem. Soc. Jpn. 1959, 32, 965-970.

21. (a) Than, S.; Maeda, H.; Irie, M.; Kikukawa, K.; Mishima, M. Int. J. Mass. Spec. 2007, 263, 205-214. (b) Maeda, H.; Irie, M.; Than, S.; Kikukawa, K.; Mishima, M. Bull. Chem. Soc. Jpn. 2007, 80, 195-203. (c) Mishima, M.; Maeda, H.; Than, S.; Irie, M.; Kikukawa, K. J. Phys. Org. Chem. 2006, 19, 616-623. (d) Fujio, M.; Alam, M. A.; Umezaki, Y.; Kikukawa, K.; Fujiyama, R.; Tsuno, Y. Bull. Chem. Soc. Jpn. 2007, 80, 2378-2383. (e) Fujio, M.; Umezaki, Y.; Alam, M. A.; Kikukawa, K.; Fujiyama, R.; Tsuno, Y. Bull. Chem. Soc. Jpn. 2006, 79, 1091-1099.

22. (a) Kevill, D. N.; D’Souza, M. J. J. Org. Chem. 2004, 69, 70447050. (b) Kevill, D. N. In The Chemistry of the Functional Groups. The Chemistry of Acyl Halides; Patai, S., Ed.; Wiley: New York, 1972; Chapter 12. (c) Kevill, D. N.; Kyong, J. B. J. Chem. Res. 2007, 4, 210-215. (d) Kevill, D. N.; Koh, H. J. J. Phys. Org. Chem. 2007, 20, 88-92. (e) Kevill, D. N.; Park, B. C.; Park, K. H.; D'Souza, M. J.; Yaakoubd, L.; Mlynarski, S. L.; Kyong, J. B. Org. Biomol. Chem. 2006, 4, 1580-1586. 